\title{
Mecanismo e Resistência à Abrasão de Compósitos à Base de Poliéster-SiC para Uso em Coroas de Polimento de Rochas Ornamentais
}

\author{
Rafaela B. Aigueira, Marcello Filgueira \\ Laboratório de Materiais Avançados, UENF
}

\begin{abstract}
Resumo: O presente trabalho apresenta o processamento e ensaios abrasivos, referentes ao desenvolvimento de compósitos à base do sistema poliéster-SiC (carbeto de silício), e a avaliação da possibilidade de sua aplicação tecnológica nas coroas de polimento de rochas ornamentais, normalmente feitas à base do compósito cimento magnesiano (SOREL)-SiC. Com esta finalidade, compósitos foram produzidos utilizando-se concentrações variáveis de SiC (5-10-20-30-50-50\%) proporcionais ao sistema poliéster-SiC, via mistura e posterior cura, mediante emprego de catalisador. Os compósitos foram submetidos a testes de desgaste, simulando uma situação de polimento de rochas ornamentais. Dentre os compósitos poliéster-SiC produzidos, as amostras que apresentaram melhores resultados foram as que possuem $50 \%$ p SiC. Estas superaram em 5 vezes as amostras de SOREL-SiC no desempenho de abrasão, porém as mesmas apresentaram um resultado 4,6 vezes maior em termos de perda de massa, levando a um "empate" no desempenho global.
\end{abstract}

Palavras-chave: Compósito abrasivo, mecanismos de desgaste, polimento.

\section{Mechanism and Wear Resistance of Polyester - SiC Based Composites for Use in Polishing Crowns of Dimension Stones}

Abstract: This work deals with the processing and abrasive tests in polyester - SiC (silicon carbide) composites, and evaluation of their possible technological application in dimension stones polishing crowns - commonly made of magnesian mortar (named SOREL) - SiC. Composites were prepared with polyester concentrations of (5-10-20-30-40-50) weight \% $\mathrm{SiC}$, by mixing and curing. The composites were submitted to wear tests, simulating a dimension stone polishing operation. Optimized performance was achieved for samples with $50 \% \mathrm{wt} \mathrm{SiC}$, which exhibited an abrasion resistance 5 times that of SOREL-SiC samples. However, the composite displayed a mass loss 4.6 times higher, thus pointing to an overall performance that is similar to that of SOREL-SiC samples.

Keywords: Abrasive composite, wear mechanisms, polishing.

\section{Introdução}

O estudo de materiais para uso em ferramentas abrasivas nas atividades de beneficiamento de rochas ornamentais, tais como desbaste, polimento e lustro vem crescendo bastante na última década ${ }^{[1]}$, acompanhando a evolução experimentada a partir da década de 80 pelas ferramentas de corte de rochas, do tipo disco serra, fios perolados, etc.

Coroas abrasivas são ferramentas empregadas para o beneficiamento de chapas de rochas ornamentais, que envolve o desbaste, polimento e lustro, etapas estas que se diferenciam basicamente pela granulometria dos abrasivos utilizados nas coroas. Essas ferramentas são feitas normalmente de partículas abrasivas de tamanhos variados, imersas em matrizes cerâmicas (argamassa de cimento), ou em matrizes poliméricas (poliéster ou epóxi). As partículas abrasivas são responsáveis pela ação de polimento e normalmente são de pó de diamante sintético (quando a matriz é polimérica), ou mais comumente de carbeto de silício (quando a matriz é SOREL). As matrizes, tanto cerâmicas quanto poliméricas, atuam como ligante, retendo as partículas abrasivas na ferramenta de polimento ${ }^{[2]}$.

O desgaste da ferramenta inicia-se através do desgaste da partícula abrasiva, causando o seu abaulamento (planificação ou embotamento do grão abrasivo). Em seguida, a matriz polimérica também sofre um desgaste que causa a diminuição da área na qual a partícula abrasiva se sustenta sobre tal matriz. Com o aumento desse desgaste até um ponto crítico, a partícula abrasiva se desprende e uma nova camada de partículas abrasivas começa a surgir. Esse desprendimento das partículas para o surgimento de uma nova camada é chamado de protusão ou "pull-out" [3].

A explicação mais antiga do mecanismo de desgaste do diamante é que pequenos fragmentos da superfície resultante, provavelmente, é constituída de uma série de asperezas cujas faces são planos de fácil clivagem ${ }^{[4]}$. Temse que a taxa de desgaste não aumenta com a temperatura, mas é dependente da direção de abrasão $0^{[5]}$. Entretanto, o

Autor para correspondência: Marcello Filgueira, Laboratório de Materiais Avançados, UENF, Av. Alberto Lamego 2000 - Pq. Califórnia, CEP: 28013-600, Campos dos Goytacazes, RJ. E-mail: marcello@uenf.br 
mecanismo de desgaste mais aceito de uma ferramenta de corte à base de diamantes impregnados em matriz ligante foi proposto por Wright e Wapler ${ }^{[6]}$, e interpretado por Davis et al ${ }^{[7]}$. Esse mecanismo é ilustrado esquematicamente na Figura1, que mostra o comportamento da altura livre (altura de protusão parte exposta, fora da matriz, responsável pelo corte) de uma partícula de diamante embebida na matriz, com o tempo, ou com a área de pedra cortada. Na região 1 ocorre o desgaste inicial da matriz e o surgimento das faces cortantes das partículas abrasivas. A região 2 é denominada zona de trabalho constante, onde ocorre apenas um leve desgaste abrasivo da matriz ligante. A região 3 é caracterizada pelo embotamento (início de planificação) do diamante e a posterior quebra de sua ponta cortante, resultando na auto-afiação da partícula abrasiva, mediante fricção contínua com a pedra. A região 4 é caracterizada pelo desgaste erosivo da matriz pela pedra, com liberação parcial das outras faces do diamante. Na região 5 ocorre a quebra da partícula, culminando com a protusão da mesma, na região 6 . Não há separação entre as regiões $4 \mathrm{e}$ 6, uma vez que a protusão das partículas (região 6) ocorre devido ao desgaste erosivo que ocorre na região 4.

$\mathrm{O}$ uso de abrasivos numa superfície sólida resulta em remoção de material. Do ponto de vista do material a ser trabalhado, o mecanismo de desgaste depende das propriedades mecânicas do sólido. Em um sólido dúctil, o mecanismo básico de desgaste está relacionado com a deformação plástica; paralelamente, a dureza é o parâmetro que governa a quantidade de material a ser removido. Entretanto, o mecanismo dominante de abrasão em material frágil depende predominantemente da fratura na superfície, de forma tal que a propriedade dominante é a tenacidade ${ }^{[8]}$.

Visando o aumento na resistência à abrasão de uma ferramenta de desbaste, polimento e lustro à base de um compósito, adições de fases duras (diamante, $\mathrm{SiC}, \mathrm{Al}_{2} \mathrm{O}_{3}$, dentre outros cerâmicos) podem ser introduzidas dentro de uma matriz dúctil ou frágil (polimérica ou cerâmica). Entretanto, as propriedades mecânicas requeridas pelo reforço e sua respectiva função, são bem diferentes para cada tipo de

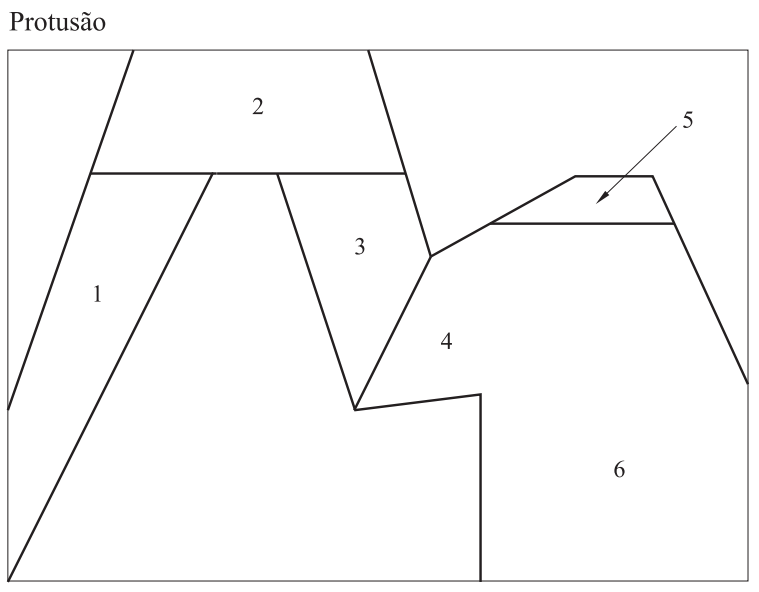

Área cortada ou tempo de corte

Figura 1. Tempo de vida hipotético de uma partícula de diamante, em termos de altura de protusão (extraído e modificado $\mathrm{de}^{[6]}$ ). matriz (dúctil ou frágil). Para uma matriz dúctil, uma fase secundária dura é necessária para reduzir o desgaste da ferramenta. Por outro lado, um reforço tenaz é necessário para aumentar a resistência à abrasão em matriz frágil, pois a presença da fase tenaz reduz a tendência de fratura superficial do compósito ${ }^{[8]}$.

O presente trabalho visa o processamento e a caracterização de um novo compósito para o polimento de rochas ornamentais e posterior teste de desgaste, frente a coroas comerciais. Além disto, pretende apresentar uma interpretação qualitativa do mecanismo de desgaste. Esses compósitos são constituídos de pó de carbeto de silício como partículas abrasivas duras, finamente dispersas em uma matriz dúctil de poliéster, fato este que atende aos comportamentos de desgaste ora mencionados. Desta forma pretende-se contribuir para o entendimento de um assunto ainda pouco explorado na literatura.

\section{Experimental}

Neste estudo são processados compósitos cuja matriz ligante é a resina poliéster, com partículas abrasivas $\mathrm{SiC}$ finamente dispersas, nos teores de 5, 10, 20,30, 40,50\% em peso. $\mathrm{O} \mathrm{SiC} \mathrm{utilizado} \mathrm{apresentou} \mathrm{tamanho} \mathrm{médio} \mathrm{de} \mathrm{partícula}$ de $23 \mu \mathrm{m}$, tamanho ideal para a última etapa de polimento de rochas ornamentais, antes do lustre e brilho final ${ }^{[2]}$, pureza igual a $99,2 \%$, e densidade $3,20 \mathrm{~g} / \mathrm{cm}^{3}$. Estas partículas foram adquiridas via empresa produtora South Bay Tecnology (SBT).

Quanto ao poliéster, trata-se de polímero comercial - tipo automotivo, adquirido do fabricante Companhia SulAmericana de Tintas e Solventes Ltda., com massa específica de $1,19 \mathrm{~g} / \mathrm{cm}^{3}$.

As misturas de poliéster - $\mathrm{SiC}$ foram feitas manualmente e para acelerar a cura da matriz, foi utilizado um catalizador oferecido pelo mesmo fabricante da resina polimérica sendo um produto à base de peróxidos. Para cada $100 \mathrm{~g}$ de poliéster, foram utilizadas 25 gotas de catalisador, segundo recomendação do fabricante. Foram preparadas 7 amostras de cada composição, cujas dimensões médias foram de $15 \mathrm{~mm}$ de altura X 12,7 mm de diâmetro. Os lotes de 7 amostras por composição foram destinados aos ensaios de desgaste, simulando a operação de polimento de rochas ornamentais. O material de ensaio foi um granito cinza, com estrutura orientada, de granulometria grossa - variando de 4 a $20 \mathrm{~mm}$, petrograficamente classificado como biotita monzogranito. Este material é constituído de $32 \%$ de quartzo, $31 \%$ de microclina microperitítico, $24 \%$ de plagioclásio, $11 \%$ de biotita, e $2 \%$ de acessórios. Apresenta densidade de $2,67 \mathrm{~g} / \mathrm{cm}^{3}$, absorção d'água de $0,35 \%$, e porosidade total de $0,93 \%$. Foi produzido um disco deste granito com diâmetro externo e interno de, respectivamente, 70 e $40 \mathrm{~cm}$, e altura $5 \mathrm{~cm}$. Este disco foi instalado horizontalmente na mesa de um simulador físico tipo AMSLER modificado-microprocessado modelo AB800-E fabricado pela CONTENCO. Cada amostra foi acoplada verticalmente ao disco de granito, em suporte com 
fixador e peso. Os parâmetros destes ensaios foram: carga vertical sobre as amostras de $5 \mathrm{kgf}$, rotação do disco de granito de 40 RPM, e tempo de ensaio de 2 minutos. Estes parâmetros foram calculados com base nos parâmetros utilizados nas politrizes industriais de rochas ornamentais, resguardando as dimensões das amostras em relação às das coroas comerciais. Durante os ensaios, o disco de granito gira na rotação desejada, e as amostras ficam paradas em um ponto, até o fim do ensaio. Antes e após os testes, a rugosidade do disco de granito é medida com um rugosímetro marca Mitutoyo de resolução $0,001 \mathrm{~mm}$. Estas medidas foram feitas em vários pontos, distantes $5 \mathrm{~mm}$ um do outro, ao longo de toda a trajetória perimetral de abrasão de cada amostra. Com base nestes resultados calculou-se o acabamento superficial do disco de granito, o desempenho de abrasão das amostras (DA), através da equação 1 , e os cálculos de perda de massa (PM) das amostras realizadas com o uso da equação 2 , que corresponde à resistência à abrasão.

$$
D A=\frac{R A-R D}{R A} \times 100
$$

Onde: RA e RD são, respectivamente, a rugosidade do granito antes e após os ensaios de abrasão, em mm.

$$
P M=\frac{M I-M F}{M I} \times 100
$$

Onde: MI e MF são, respectivamente, as massas das amostras antes e após os ensaios de abrasão, em gramas.

As microestruturas dos compósitos após os ensaios de abrasão foram analisadas via microscopia eletrônica de varredura ( MEV ZEISS DSM 962). É válido ressaltar que lotes de amostras retiradas de coroa comercial à base de cimento magnesiano (SOREL) $-20 \%$ em peso $\mathrm{SiC}$ foram ensaiadas nas mesmas condições das amostras aqui produzidas, a efeito comparativo.

\section{Resultados e Discussão}

\section{Ensaios de polimento - desgaste por abrasão}

A Tabela 1 fornece resultados de desempenho de abrasão e perda de massa percentual dos compósitos processados, e do compósito SOREL-20\% peso SIC, retirado de coroas comerciais, calculados via uso das equações 1 e 2 .

Pode-se claramente observar que, do ponto de vista do desempenho da abrasão, os compósitos poliéster $\mathrm{SiC}$ são superiores ao compósito SOREL $-20 \%$ peso $\mathrm{SiC}$ das coroas comerciais. Neste tocante, as amostras com composição poliéster $-50 \%$ peso $\mathrm{SiC}$ apresentaram desempenho da ordem de 5 vezes superior ao compósito comercial, o que já é um indicativo do potencial tecnológico deste compósito. Por outro lado, quando se trata da perda de massa dos compósitos, observou-se que a menor perda de massa verificada nas amostras poliéster- $\mathrm{SiC}$, ocorreu para a composição poliéster $-50 \%$ peso $\mathrm{SiC}$, que foi aproximadamente 4,6 vezes superior a da de SOREL - $20 \%$ peso SiC. Desta forma, considerando o desvio-padrão, observa-se que há um empate em termos de

\begin{tabular}{|c|c|c|c|}
\hline \multicolumn{2}{|c|}{ Amostras } & \multirow{2}{*}{$\frac{\text { DA }(\%)}{84,9 \pm 12,3}$} & \multirow{2}{*}{$\begin{array}{c}\text { PM (\%) } \\
51,6 \pm 2,8\end{array}$} \\
\hline Poliéster & $-5 \%$ peso $\mathrm{SiC}$ & & \\
\hline Poliéster & $-10 \%$ peso $\mathrm{SiC}$ & $103,2 \pm 7,8$ & $43,2 \pm 2,2$ \\
\hline Poliéster & $-20 \%$ peso $\mathrm{SiC}$ & $142,1 \pm 21,4$ & $39,9 \pm 1,3$ \\
\hline Poliéster & $-30 \%$ peso $\mathrm{SiC}$ & $194,7 \pm 17,6$ & $35,8 \pm 1,4$ \\
\hline Poliéster & $-40 \%$ peso $\mathrm{SiC}$ & $235,4 \pm 13,7$ & $34,0 \pm 1,2$ \\
\hline Poliéster & $-50 \%$ peso $\mathrm{SiC}$ & $421,8 \pm 19,1$ & $31,2 \pm 0,9$ \\
\hline SOREL & $-20 \%$ peso $\mathrm{SiC}$ & $81,9 \pm 8,8$ & $6,8 \pm 0,6$ \\
\hline
\end{tabular}

Tabela 1. Desempenho de abrasão e perda de massa das amostras ensaiadas

desempenho global destes dois compósitos. Para avaliar qual é comercialmente superior, deve ser feita uma análise de viabilidade econômica, e tempo de vida útil dos compósitos, o que não é alvo desta pesquisa.

De acordo com os resultados observados na Tabela 1, e em conformidade com Luo ${ }^{[9]}$, o aumento do teor de partículas abrasivas na matriz dos compósitos promove uma melhora crescente no desempenho da ferramenta até um certo limite, e a partir deste, o desempenho começa a cair. Este valor limite é de $50 \%$ em peso, segundo $\mathrm{Luo}^{[9]}$, quando do estudo da preparação e testes de rebolos do sistema diamante -epóxi.

\section{Superfícies de desgaste dos compósitos abrasivos}

A Figura 2 mostra a superfície de desgaste do compósito poliéster contendo $5 \%$ em peso de $\mathrm{SiC}$. Pode-se observar que a matriz apresentou um satisfatório trabalho de adesão para com as partículas abrasivas (vide setas na Figura 2), resultando em desempenho de abrasão da mesma ordem daquele do compósito das corôas comerciais, como mostra a Tabela 1 . Entretanto, a mesma tabela apresenta para este compósito

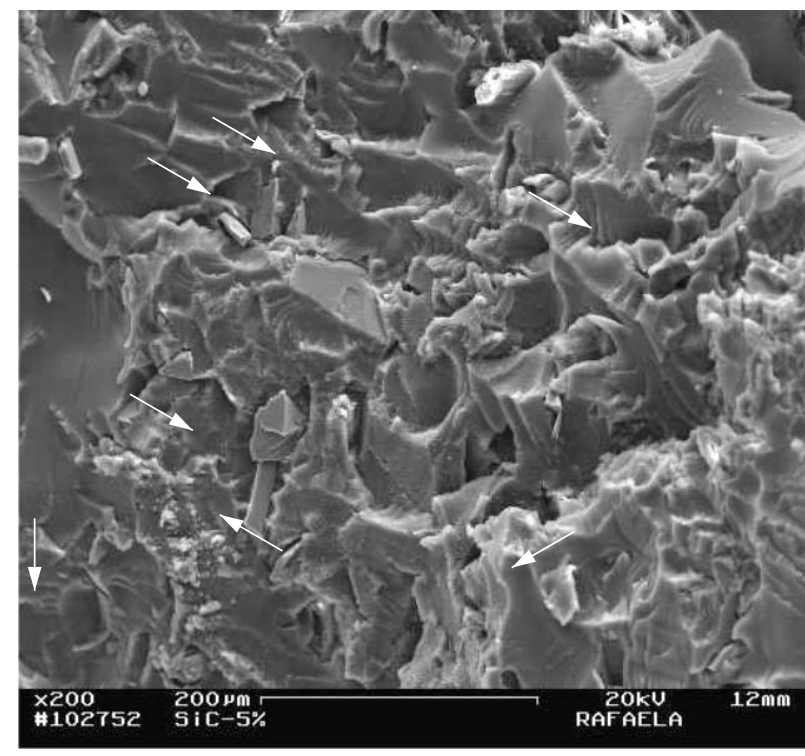

Figura 2. MEV da superfície de desgaste do compósito à base do sistema de poliéster $-5 \%$ p SiC. 
uma perda de massa alta em relação aos demais compósitos, pois com o baixo teor de $\mathrm{SiC}$, a matriz polimérica fica desprotegida - este é o caso em que o desgaste da matriz domina o mecanismo de desgaste da ferramenta de corte.

Os compósitos com 10, 20 e $30 \%$ em peso de $\mathrm{SiC}$, apresentam uma superfície de desgaste bastante deteriorada, pois como pode ser observado nas Figs. 3, 4 e 5 respectivamente, a matriz de poliéster apresenta-se muito degradada e com poucas partículas abrasivas (vide setas nas Figuras 3-5). Isto é justificado pelo fato que a matriz ao se degradar, começou a cobrir as partículas de $\mathrm{SiC}$ que estavam surgindo na superfície da amostra, e em função disto os aumentos apresentados nas Figuras 3-5 são superiores aos das outras figuras, com o objetivo de mostrar as partículas sendo encobertas pela matriz. Além disso, outro fator que contribuiu

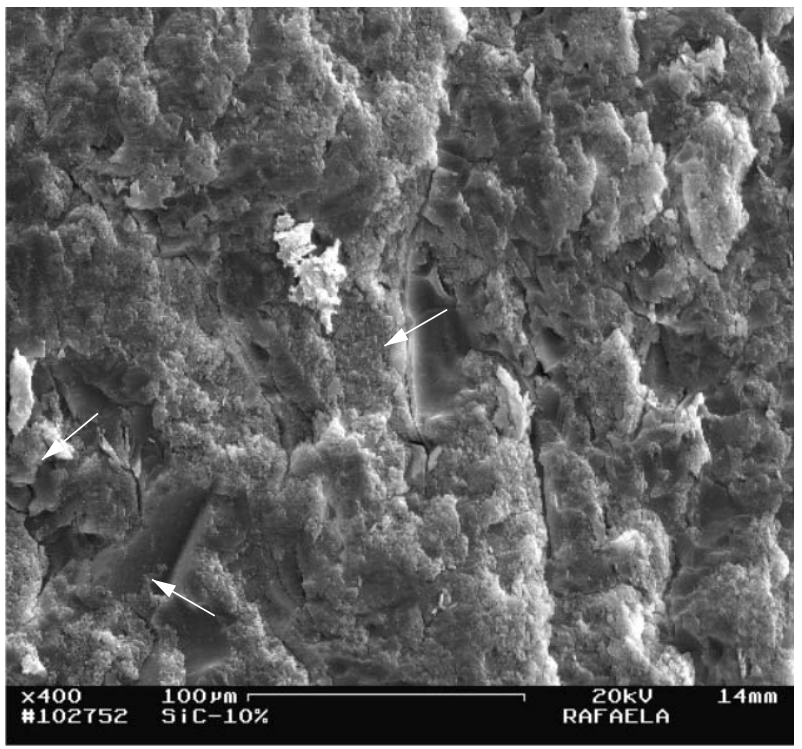

Figura 3. MEV da superfície de desgaste do compósito à base do sistema de poliéster $-10 \%$ p SiC.

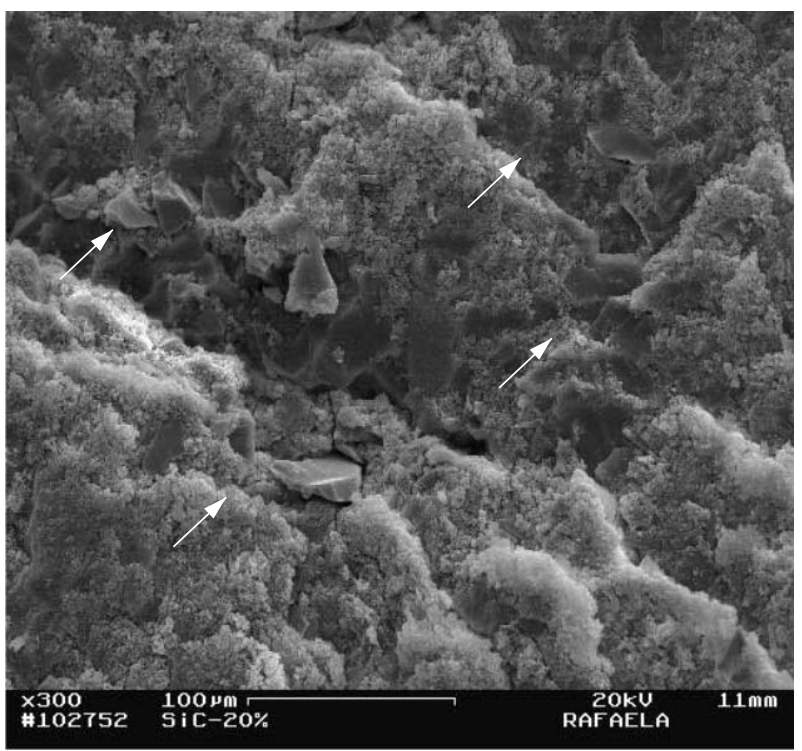

Figura 4. MEV da superfície de desgaste do compósito à base do sistema de poliéster $-20 \%$ p SiC.

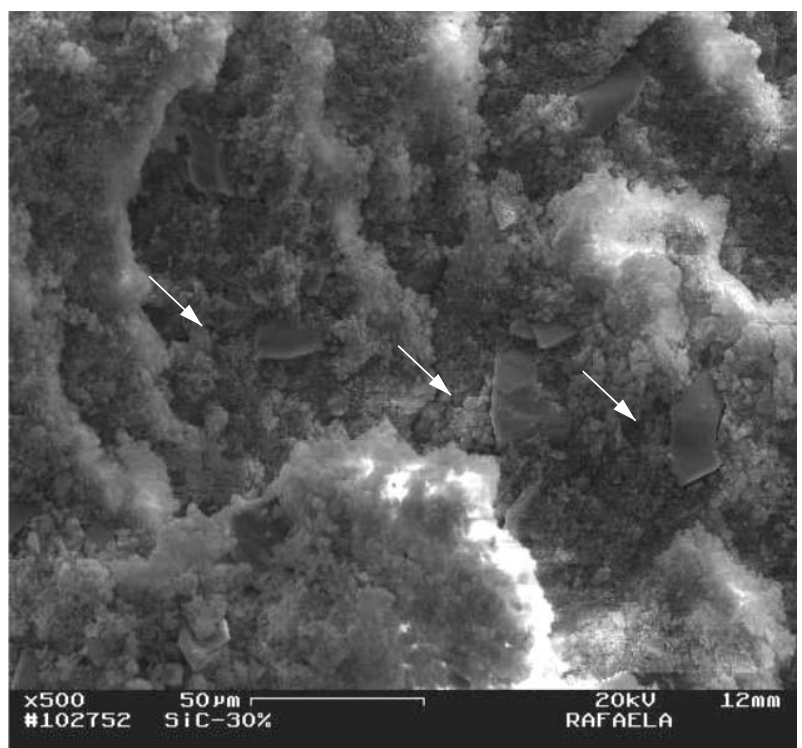

Figura 5. MEV da superfície de desgaste do compósito à base do sistema de poliéster $-30 \%$ p SiC

para o encobrimento das partículas foi o fato destas amostras apresentarem um volume de matriz muito maior que o volume das partículas abrasivas. Fica claro que o mecanismo de desgaste da matriz para os compósitos das Figuras 3-5 é por plasticidade, pois com os pontos de aquecimento por atrito, a matriz começa a se degradar, e a cobrir as partículas abrasivas. Esta deterioração dúctil da matriz promove a soltura prematura das partículas abrasivas que estão na superfície,deixando, obviamente vazios na microestrutura.

Já os compósitos com 40 e $50 \%$ em peso $\mathrm{SiC}$ apresentaram uma matriz com uma degradação menor, o que é observado nas Figuras 6 e 7, respectivamente. Isto é justificado pelo fato das amostras apresentarem um volume de matriz menor que os demais compósitos do sistema poliéster-SiC, em relação ao volume das partículas abrasivas, ou seja, o volume da matriz degradada não foi suficiente para encobrir as partículas que iam surgindo na superfície da amostra. Em função disto, as superfícies de desgaste apresentaram um maior volume de partículas aderidas à matriz, e portanto um desempenho de abrasão superior as demais amostras dos sistemas poliéster$\mathrm{SiC}_{\beta}$, e a amostra de sorel- $20 \% \mathrm{SiC}_{\beta}$, (vide Tabela 1).

As amostras de SOREL-20\%p SiC (retiradas de coroa comercial), apresentaram uma superfície de desgaste pouco degradada, como pode ser observado na Figura 8. Esta micrografia revela também que o poder de adesão da matriz foi satisfatório, pois pode ser visto claramente muitas partículas abrasivas aderidas à matriz (vide setas), o que justifica a menor perda de massa em relação ao sistema poliéster-SiC, como pode ser observado na Tabela 1. Além disso, a superfície de desgaste desta amostra revela que a degradação da superfície ocorre por liberação de finas “escamas" da matriz (vide círculo Figura 8), podendo-se também notar claramente a direção de desgaste do compósito, o que não pode ser observados nas demais amostras. Assim tem-se o desgaste frágil, com a superfície da matriz permanecendo plana. Isto é de se esperar, pois a matriz é de 
natureza cerâmica, não apresentando qualquer indício de dano térmico, apresentando, então, mecanismos de desgaste diferente da matriz polimérica.

\section{Mecanismo de desgaste dos compósitos abrasivos}

Para estas duas classes de compósitos, poliéster-SiC, matriz dúctil - abrasivo de alta dureza, e SOREL-SiC, matriz frágil abrasivo de alta dureza, e para o uso em polimento de rochas ornamentais, o mecanismo de desgaste é definido como: 1) abrasão inicial da matriz ligante; 2) início do corte da pedra pelas partículas abrasivas; 3) embotamento das partículas até a planificação e posterior desprendimento da matriz - caso de uma satisfatória aderência matriz-partículas (matriz dúctil partículas de alta dureza), vide Figura 7. No caso de má aderência, as partículas, mesmo no inicio do polimento sofrem

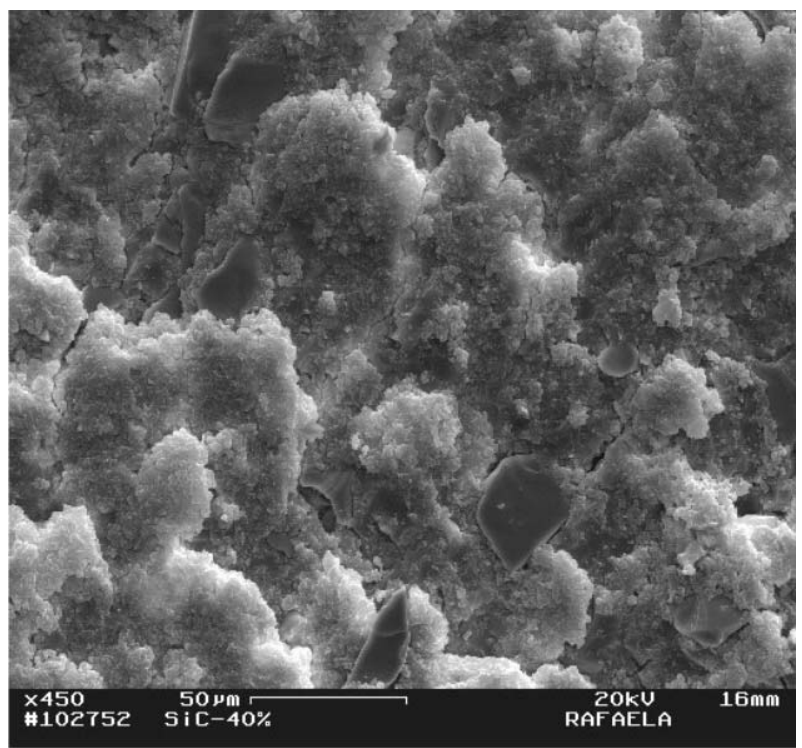

Figura 6. MEV da superfície de desgaste do compósito à base do sistema de poliéster $-40 \%$ p SiC.

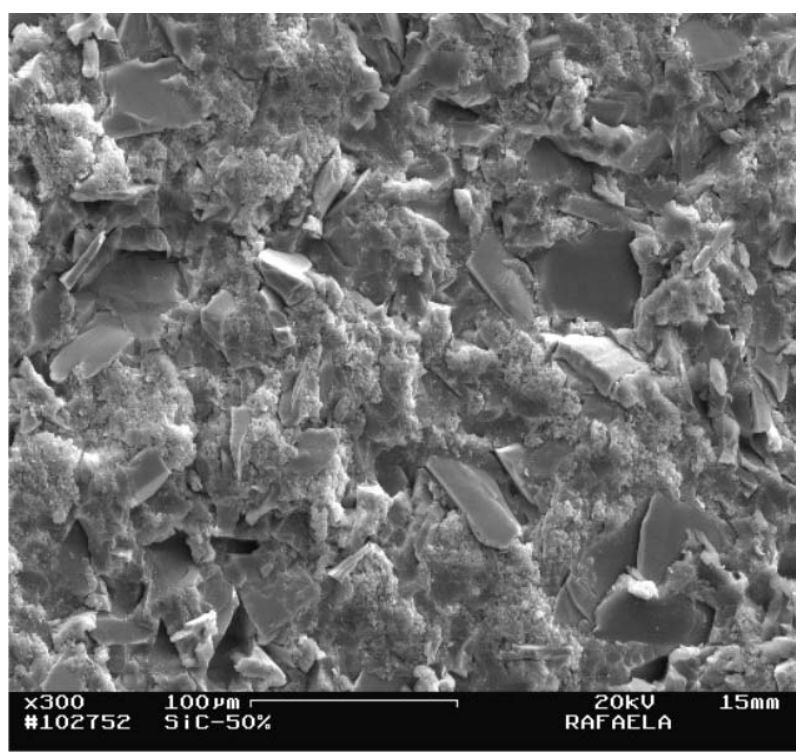

Figura 7. MEV da superfície de desgaste do compósito à base do sistema de poliéster $-50 \%$ p SiC.

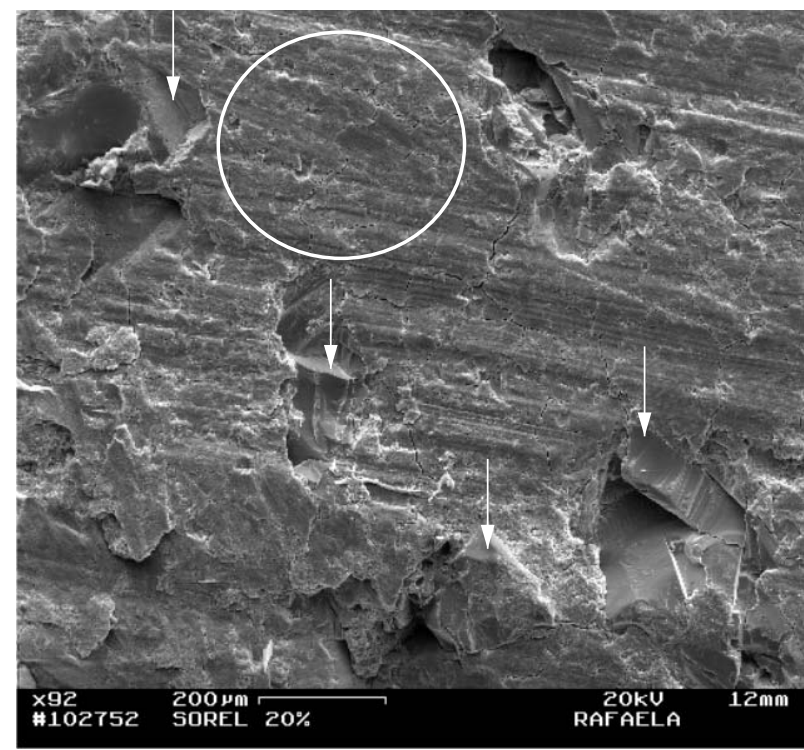

Figura 8. MEV da superfície de desgaste da coroa comercial à base do sistema sorel $-20 \%$ p SiC.

desprendimento, o que acarreta um desgaste prematuro e excessivo da matriz (matriz frágil - particulas de alta dureza) vide Figuras 8; 4) após o desprendimento, ocorreu um desgaste da matriz polimérica, e o surgimento de novas faces cortantes de outras partículas que estavam no "bulk", reiniciando o ciclo.

No mecanismo de desgaste acima descrito, o teor de partículas abrasivas no compósito apresenta enorme significado. Com o aumento deste teor, aumenta também o desempenho e vida útil da ferramenta, até um certo valor estequiométrico. Com o aumento do teor de partículas abrasivas, além do limite, a ferramenta sofre perda em suas propriedades, face à redução da área útil da matriz para a "ancoragem" das partículas abrasivas. Isto reduz drasticamente a aderência entre a matriz e as partículas, pois a tensão resistente da adesão é inversamente proporcional à área resistente de "ancoragem" - levando as partículas a se desprenderem prematuramente.

Do ponto de vista do mecanismo de desgaste dos compósitos, e à luz das micrografias 2-8, verifica-se que não há qualquer indício de processo de auto-afiação das partículas abrasivas, contrariamente ao mecanismo de desgaste observado nas refs.[6] e [7], porém em pleno acordo com Warnecke e Wimmer $^{[10]}$, ao avaliar o desgaste de coroa de matriz polimérica dúctil com diamante impregnado, durante o polimento de cerâmicas avançadas. Deve-se considerar também que o polimento de rochas ornamentais ocorre pela ação combinada das forças vertical e rotação impostas à ferramenta, que não ocorre nos processos de corte, o que torna o desgaste ainda mais drástico do que no caso descrito por Wright e Wapler ${ }^{[6]} \mathrm{e}$ por Davis et al ${ }^{[7]}$, ou seja, devido ao giro relativo ferramentapedra, ocorre soltura prematura de partículas abrasivas.

\section{Conclusões}

Neste trabalho exploratório destacam-se as seguintes conclusões principais: 
1. A rota desenvolvida para o processamento de compósitos à base do sistema poliéster-SiC, para a aplicação como coroas abrasivas de desbaste e polimento de placas de rochas ornamentais, foi alcançada com sucesso sendo realizada com simplicidade e rapidez;

2. No mecanismo de desgaste dos compósitos estudados não ocorre auto-afiação das partículas abrasivas, sendo este desgaste dominado pelo comportamento dúctil da matriz poliéster, propiciando uma aderência satisfatória com o $\mathrm{SiC}$, o qual por sua vez sofreu aplainamento e soltura durante o polimento, mas propiciando o surgimento de novas partículas cortantes que se encontravam no "bulk" do compósito;

3. Dentre os compósitos à base do sistema poliéster-SiC, comparando os resultados obtidos dos testes de desgaste juntamente com a análise das micrografias, as amostras que apresentaram melhor resultado foram as que possuem $50 \%$ p SiC. As amostras com 50\%p SiC, apesar de superarem em 5 vezes a coroa abrasiva no desempenho de abrasão, as mesmas apresentaram um resultado 4,6 vezes inferior ao da coroa comercial em termos de perda de massa, levando a um "empate" no desempenho global.

\section{Referências Bibliográficas}

1. Xu, X. - Experimental study on temperatures and energy partition at the diamond-granite interface in grinding. Tribology International. n.34. pp.419-426 (2001).

2. Aigueira, R. B.; Bobrovnitchii, G. S. \& Filgueira, M Processamento de um compósito abrasivo à base do sistema $\mathrm{SiC}$-â - poliéster para polimento em rochas ornamentais. Anais do $59^{\circ}$ Congresso Anual da ABM. pp.1527-1535 (2004).

3. Azeredo, S. R. - Processamento de Corôas Abrasivas do Sistema Sílica-Poliéster para Aplicação no Desbaste de Pedras Ornamentais, Monografia do LAMAV/ UENF, p. 32 (2002).

4. Tolkowsky, M. - D. Sc. Thesis, University of London (1920).

5. Wilks, J. \& Wilks, E. M. - Abrasion and wear of diamond, in J.E. Field (ed.), Properties of Diamond, Academic Press, London, p. 351 - 381 (1979).

6. Wright, D. N. \& Wapler, H. - Investigations and prediction of diamond wear when sawing. Annals of the CIRP. V.35. n.1. pp.239-244 (1986).

7. Davis, P. R. et al. - An indicator system for saw grit. IDR. n.3. pp.78-87 (1996).

8. Lee, G. Y et al. - A physically-based abrasive wear model for composite materials. Wear. N.252. pp.322-331 (2002).

9. Luo, S. Y. - Effect of fillers of resin-bonded composites on diamond retention and wear behavior. Wear. N.236. pp.339-349 (1999).

10. Warnecke, G. \& Wimmer, J. - Stock removal and wear in deep grinding high-performance ceramics. IDR. n.3. pp. 126-132 (1995).

Enviado: 14/06/05

Reenviado: 01/02/06

Aprovado: 14/02/06 